\title{
Structural Modeling of the Value of Patent
}

\author{
Jun SUZUKI* \\ Research Institute of Economy, Trade and Industry (RIETI), and \\ National Graduate Institute for Policy Studies (GRIPS)
}

\begin{abstract}
There is a considerable volume of prior research on the relationship between innovation and patents. Those research studies reveal that patents contain a great deal of noise, and unless a correction is made in terms of the value of individual patents, a simple count of the number of patents does not constitute a very useful indicator. From research that has been conducted for the purpose of finding such an indicator to show the value of individual patents (that is, research to identify the characteristics of valuable patents), many kinds of value indicators have been proposed. Nevertheless, research hitherto has focused primarily on business or private value derived from the possession of patents, and little attention has been paid to value in terms of technical knowledge or social value. In a survey of inventors conducted by RIETI in 2007 , terminology describing broad concepts was used when questioning inventors about the value of individual patents, and this has provided an excellent opportunity to analyze the multiple factors lying behind the value of patents and how they impact one another.

The purpose of this research is to use data from the RIETI survey of inventors and structural equation modeling methods to elucidate the relationships between the technological and business value of patents, and the latent factors that influence them. The findings show that a scientific-technological motive for inventors would have a positive effect on both the business and technological value, meanwhile, the monetary or promotion motive would not have any direct effects on the value of a patent. The model also suggests that academic linkage would have a strong positive effect on the technological value but a weak negative effect on the business value. Furthermore, these relationships differ more markedly according to technological field.
\end{abstract}

\section{Keywords: Patent value, Inventor survey, Structural Equation Modeling}

\footnotetext{
*Tel. : +81-3-6439-6116; Fax. : +81-3-6439-6330

e-mail address : jsuzuki@grips.ac.jp National Graduate Institute for Policy Studies, 7-22-1 Roppongi, Minato-ku, Tokyo, 106-8677 Japan
} 


\section{Introduction}

Beginning first with Schmookler and then with Griliches, many researchers have used quantitative and qualitative analysis of patenting data for analysis of innovative activities. Data on patents is publicly available and has accumulated continuously in a uniform manner over a number of years. A globally uniform format and technological classification have allowed diverse analytical approaches to emerge, and have played an important role in the development of experimental studies of innovation. However, the nature of patent data is that some high value individual patents can be prejudicial to the overall distribution pattern; namely, that with the exception of a small number of patents, the value of most patents is low. According to research by Pakes and Schankerman (1986) around half the value of all patents is from $5 \%$ of patents. Due to this, databases which use an aggregate total weight for all patents (for instance, the number of patent applications by one company over the course of a year or comparing that with other companies) do not contain much information. In particular, the "Publication of Unexamined Patent Applications" available 18 months after filing is offered just as submitted by applicants without any validation by examiners, therefore contains a lot of "noise".

Weaknesses within this kind of patent data began to be corrected as their use became a proxy indicator for innovative activity as researchers began to use them from the latter half of the 1990s, triggering a lively body of research on patents (see the next section). From these researches it was possible to assess the various facets for the values of patent. However, until now empirical research specifically on patent value from various aspects has been immature.

The 2007 survey of inventors performed by RIETI (from hereon: RIETI survey; for an outline see: Nagaoka and Tsukada (2007) asked specific questions regarding the value of patents to inventors. This was the first such trial experiment in Japan. The question used in the survey was:

Question 6.1. Among the technical accomplishments in your technological field during the same period as you invented, how would you rate the economic value of your patent?

In posing this question, the use of the term "economic value" is considered to be somewhat broader than the more limited "monetary value" term employed in the aforementioned European surveys. The RIETI survey used this terminology in light of Japan's own circumstances. In order to receive responses from corporate based inventors, the RIETI survey needs cooperation from the applicant company as the right holder. In many cases, for companies they are passive over the specific value of individual patents ${ }^{1}$. However,

\footnotetext{
${ }^{1}$ Established in Article 35 of the Patent Law, issues surrounding "compensation for reasonable value" are
} 
unwittingly the use of the wide general terminology provides a useful opportunity to test and analyze what influence a host of factors have on the value of patents.

Using data from the RIETI inventor's survey, this research will seek to shed light on the relationship and influence of the technological value and business value (discussed later) of patents.

The structure of this paper is as follows. Firstly, in Section 2, relevant prior research on the value of patents will be reviewed. Section 3 will present the structure and technique for the data analysis. In Section 4, preliminary consideration will be given to the multi-variate regression analysis and the modeling. Section 5 presents the results obtained from the analysis and the implications of the research.

\section{Prior Research on the Value of Patents}

Regarding innovation and patent indicators, a large body of prior research has accumulated. An early pioneer of such analysis was Schmookler, who undertook research on technology in the railroad, agriculture and the petroleum industrial sectors through chronological comparative analysis of the number of patents, finding that demand for inventions had a large influence on economic activities (Schmookler 1966). One of the leading figures within this field, and who performed extensive research on patent indicators was Griliches. In a comprehensive review of the literature performed in 1990, Griliches could find practically no correlation between a simple index of patent values and the valuation of a company on the stock market, stating that ""the needle might be there, but the haystack is very large" (Griliches 1990). Theoretically, the number of patent acquisitions by firms can be thought of as an indicator for the outputs from research and development, but without attaching weight on the value there is significant "noise" making it difficult to obtain useful information. To acknowledge the nature of this issue, researchers in North America and Europe began to perform further experimental research, a focus of which was to correct partial valuations of patents, and to clarify the role of patents as indicators of innovation.

Lerner (1994) used a number of individual patent classes (IPC subclasses) and used information presented on the patent cover to measure the technological scope of each patent, to which he then allocated weights. For 173 bio-venture companies in the US, he weighted the importance of the patent portfolio by the size of venture capital to test the statistical significance and any positive correlations. However, the idea to use the technological scope and attachment of weight to patents saw Lanjouw and Schankermann (1997) perform research

influencing the number of lawsuit problems between employer and employee. 
on patent infringement lawsuits and the relationship with technological scope; although at the present time this relationship has been denied in detailed research of German patents by Harhoff et al. (2008).

As a general rule it is necessary to acquire patent rights in each country, and for these inventions the number of countries in which patent rights have been acquired can be evaluated to assess the geological scope of patent values. With important inventions there is a tendency for processing and translating the patent so that rights can be acquired that apply in a number of countries. For making an indicator of the geographical scope, the idea of a "patent family" is frequently employed. There are several definitions of a "patent family" which can create some opacity, but in basic terms it can be seen as those patents where the priority insistence is applied to claims in one country (based on the Paris Treaty) as the basis for applications in other countries. That is, the outline of the invention is the same but patents are obtained in other countries leading to a family size based on the original patent. Based on the Paris Treaty, the patent family size can be known in 12+18 month from the priority date. Guellec and Van Pottelsberghe de la Potterie (2000) have shown the correlation between the ratio of registrations and patent family size. Also, Harhoff et al. (2003) used a questionnaire survey to perform a financial assessment of the owners of patent rights and observed a correlation between monetary value and patent family size.

After a patent has been conferred, the length of duration for the maintenance of patent rights can be thought of as an indicator of the business value of a patent. For this, it is common for the patentee to pay an annual fee for maintaining the patent over the course of the 20 duration for a patent (requiring sufficient cash flow over the future for the patent) and it is likely that many patents will be abandoned during this period. Lanjouw and Schankerman (2004) showed that there was a powerful correlation between patent family size and the maintenance period. However, there are large differences between technological field in the period over which property rights are maintained due to the speed of technological change, corporate strategy, the economic environment and other external factors. Exemption or reductions to the maintenance fee can have a large influence on government owned patents, university patents and those by small and medium sized enterprises. Also, indicators on the duration and character of patent right maintenance after a long period are difficult to obtain.

A widely recognized indicator of the usefulness of individual patent values is the number of forward citations; namely, the number of citations received by an inventor or patent examiner. From this, based on the assumption that high-value information is included in patents, successive inventors and patent examiners will cite the literature; at the same time this indicator is widely used to measure the impact of scientific publications. However, for this indicator and the accumulation of forward citations a lengthy time period is required, and if 
there exists highly citing group for certain prior patents, there could be a upward bias (for instance, there is a high frequency for within-firm patent citation; and the larger the company is, the greater the bias is expected). Trajtenberg (1990), Hall, Jaffe, and Trajtenberg (2002), Hall, Jaffe, and Trajtenberg (2005) have proposed using forward citations of patents as a method for correcting individual patent values.

In addition, research on patent value and the correlation between counts of the number of claims, opposition from rival firms, or the number of appeals for invalidations, backward citations (citations by inventors or examiners to prior patents), science linkage (citations by inventors or examiners to prior scientific papers) has been performed (see, for instance: Harhoff et al, 2003, Trajtenberg et al, 1997, Narin et al, 1997).

The aforementioned large-scale PatVal survey of inventors patent value implemented in six large European countries (Germany, France, the UK, Italy, Holland, Spain) in 2003/2004 has contributed to the accumulation of some of the prior research that has been presented above (PatVal-EU 2005; Giuri et al 2007). This survey collected over 9,000 responses and has permitted research on many fronts (EC Technical Report 2005, 2006). The PatVal survey in Europe triggered the RIETI survey in Japan, and using the same survey construction and items consistently should allow for comparison between the two data sets. As Nagaoka and Tsukuda (2007) have noted, there is now a broadly similar survey being implemented in the US and a second survey is now being planned in Europe.

Concerning patent value in the PatVal-EU survey, this is based on the assumed monetary value (the virtual value) of a patent by the inventor, who is asked to explain this in response to a question. Specifically, the following question is used:

This is a hypothetical question. "Suppose that on the day in which this patent was granted, the applicant had all the information about the value of the patent that is available today. In case a potential competitor of the applicant was interested in buying the patent, what would be the minimum price (in Euro) the applicant should demand?"

In the PatVal-EU survey it was anticipated that there would be an uneven distribution of high patent values (with more than one opposition received or forward citations to patents) and some oversampling. Furthermore, because inventors were asked to evaluate the value of their patents, it was anticipated that there would be some inventor bias in the value estimation; in the survey implemented in France the value of similar patents that had been applied for by the inventor (or company) were matched and the values verified and compared. From this it was found that although there was some bias by inventors, the influence of this was not largely significant. 
From the aggregate results and analysis of the PatVal-EU survey, both from the number of forward and backward citations, and the number of claims, until now each type of value indicator has been found to have a correlation. Attributes such as academic background, quantity of inventions, the number of patents produced, the maximum value (largest monetary value of various patents) and other indirect influences have been considered and clarified (an inventor with a lot of inventions has a larger maximum patent value in comparison to others). On the other hand, the attributes which influence the production and "average value" of inventions by inventors are not clearly known.

For measuring the above types of index (for patent value), what sort of component should first be introduced and how should these be constructed? Within this field there are a large number of researchers, and the construction of factors for "patent value" or "importance" have been put in place.

In the aforementioned review by Griliches, in the opening section it is stated that it is an "obvious fact" that there are large differences in the technological and economic value of individual patents. However, economic value in Griliches review was focused primarily on the individual private value of exclusive rights. Trajtenberg (1990), citing the description of the patent inspection process in the Office of Technology Assessment and Forecast (1976) report, noted that the number of forward citations to patents is the sufficient foundation for latent technological importance. It can probably be stated that the economical success or at least the expected value indicator is useful. Harhoff et al. (2003) shed light on the value of patents to business potential (such as corporate technologies and the defense or strategic value of patents through blocking to competitors). Lanjouw and Schankermann (2004) developed a synthetic index including patent family size, forward citation and backward citation, which became an indicator "to reflect the importance of technology to innovation and market opportunities".

In this way, "patent value" has mainly come to be seen as the basis of the value of invention and technological knowledge, or technological value. Those patents that are used or possessed (for new products, processes or licensed; or have the resemblance of blocking other firms' technologies) have "business value" or "private value". Until now, most of the above mentioned empirical research has focused on the latter, through focusing above all upon business value. Furthermore, Harhoff et al (2003) stated that in general researchers have used several indicators avoiding endogeneity problems prudently. For instance, it is assumed that there is a positive correlation between the number of inventors and patent values, but should the number of researchers in the field increase in the future then it is possible that the ratio of patent citations will also increase, suggesting a bias in the number of forward citations. Also, thinking of the business value of patents as a variable with regard of the aforementioned 
period in which patents are maintained, patents maintained over an extended period may stimulate or attract the interest of other researchers, leading to a higher evaluation of the technology. According to an investigation by Arora and Ceccagnoli (2006), simultaneous equation estimations of the influence of the special characteristics of decision-making towards licensing and patent acquisition by firms and industry was undertaken, but they did not touch upon the technological value that a patent may possess.

This research will use structural equation modeling (SEM) and employ the use of intuitive path diagrams to analyze the components of patent value. In the next section the data, variables, and analytical method will be explained.

\section{Data, Variables and Analytical Method}

This research draws on the 5,278 sample cases used in the RIETI survey, covering 5,250 inventor responses regarding patents from 1995, and statistical data from a patent database. Drawing on the RIETI survey responses, in Figure 1 data by technological field is presented (based on US patent classification; see: Nagaoka and Tsuda 2007). In Section 4 these technological fields will form the basis for the analysis.

Figure 1

The RIETI survey data has an extensive coverage, and in each section there are a number of questions that are linked together which provide statistical data that can be synthesized to create 18 types of variable (Table 1 ).

\section{(1) Patent Value Variables}

Val_Dom (Inventor evaluation of economic value of patent): This variable is from Q6.11 in the survey, which has four ordinal category responses. Unfortunately this contained numerous data problems. In the RIETI inventor survey, respondents were requested to evaluate the domestic value and international value of their patent; as there were generally no major differences between the two, this research used the domestic valuation data.

Triadic_3 (existence of triadic applications/standards/important patents): This variable is an attribute of the survey sample data-source and with three ordinal categories. The sample consists of patent applications in Japan, America and Europe, or "triadic patents" which are divided from other applications. With the exception of these triadic patents, those patents that have become the basis for standardization or have been recognized as very important by experts within that field were included. Theoretically, as stated before this can be thought as a 
means of verification of the "family size".

Use_or5 (Existence of use of patent within the company) This variable has five ordinal categories. The division of the categories is basically based upon Q6.3, and is joined with the outline for the responses to Q6.8. In the case where the patent is not enacted by the company, categories on the reason for this corporate strategy (withdrawal from that particular research area etc.) or to block the use of the patent and technology to other competitors with the patent gaining strategic importance were included.

Lic_or5 (Existence of applicability of patent licensing): this variable has five ordinal categories. The category division is based on Q6.6, but also includes the outline from the above mentioned Q6.8. In the cases where there was no licensing there is a division of those patents with strategic value.

Paper_3 (Existence of publication in scientific journals of the invention outline): This variable has three ordinal categories. The division of categories is drawn from Q6.9, but in general publications by researchers in companies are subject to restraints; in synthesis with Q6.8, in the cases where scientific publication did not occur a category that included "technological level was not high" was included.

Ln_claim (The breadth of scope for patent coverage) : This variable is a natural logarithm of an integer of 1 , or more is the scale variable which takes discrete value. This data was not drawn from the survey data, but the number of claims when applying for a particular patent from publicly information on unexamined patents was used.

I_fc5_tr (The number of citations received by the inventor five years after application): This variable has three categories. Drawing on the Tamada et al. (2003) method of calculating the number of patent citations from the patent description On the patent explanation form, the number of forward citations to the appropriate patent was assessed(Suzuki et. al., 2008). The value for this was divided into three categories. This citation data in aggregate at April 2005 covers patent applications in 2000 and 2001 but as their citation period had not expired there is a downward bias in these statistics. In this research, revisions for downward bias as performed in Hall et al. (2002) is not performed; there was insufficient data for patent applications in 2000 and 2001 for this variable.

Expct_use (The expected use of the acquired rights; use within the company): This variable comprises two variables, from 5 ordinal categories. The categories have been divided based on the outline for Q6.2 although there were many missing data. This variable concerns the expected use for the invention at the time of patent acquisition for the company, and shows the recognized potential and utility value of the patent by the inventor.

Expct_bloc (The purpose of the invention rights; blocking): This variable concerns the 
expected purpose of the invention rights with regard to the ability to block technological development by other companies. It concerns the understanding of the strategic value of the patent.

\section{(2) Variables concerning Inventor Motivation}

Mot_sci (The motive for invention; the contribution and progress of science and technology): This variable has five ordinal categories. The category division is based on the responses to Q5.1 in the survey. This variable looks at the motivation for the social contribution of science and technology research results since it was first initiated.

Mot_tech (The motive for invention: overcoming research challenges and issues): This variable concerns the attempts to overcome technological challenges by researchers and technologists, and the strong interest they have held for the first research results.

Mot_car (The motive for invention: career and status advancement): This variable concerns the career trajectory and status of inventors, as well as the motivations for career advancement since the highpoint of research results.

Mot_mony (The motive for invention: financial remuneration): This variable concerns financial remuneration and the profit incentive since the high point of the research results.

\section{(3) Academic Linkage Variables}

AcNW (Relationship with public research institutes and universities): This variable is from Q4.8 in the survey "existence of collaborative invention with university researcher and collaborative research"; Q.10 "existence of research cooperation with university/ies"; and, Q17, "existence of use of public funding", where respondents could select from two values (either: " $0=$ no";" $1=$ yes") which provides four categories. The smallest value is 0 and the largest value is 3; and, along with expectations there is a skew distribution towards zero values amongst the sample responses.

Num_SL (Science Linkage): Similar to the method this variable and $I \_f c 5 \_t r$, data was drawn from the patent description on academic publication citations to create a data-source. According to the number of citations, a categorization was performed whereby no citations = 0,1 citation $=1$, and more than 2 citations $=2$. This variable had a similar skew to $A c N W$.

InConc_sci (Research idea conception and source of knowledge; science and technology publications): this variable includes 3 parameters and 6 ordinal categories; of these but some of these were not used due to data difficulties. Of the other categories, these are based on 
responses from Q4.12 in the survey addressing the usefulness of the scientific literature for the conception of the idea.

InConc_ac (Research idea conception and source of knowledge: universities): This variable concerns the acquisition of the research conception from universities or other institutes of education through tacit knowledge (from other sources except scientific publications).

InConc_gov (Research idea conception and source of knowledge: public institutes): This variable concerns the conception for the research from sources other than universities, such as public research organizations through tacit knowledge (from other sources except scientific publications).

From the above observations, descriptive statistics related to each variable will be presented in Table 2.

[Table 1.]

[Table 2.]

\section{(4) Structural Equation Modeling.}

Structural Equation Modeling (SEM) is a technique which is developed as an expansion of factor analysis that can handle difficult latent factors, and is derived from observing at first hand research on the psychology, and pedagogy fields (Joreskog 1978). However, through the diffusion of high level handbooks and software the usability has now become widely recognized and a number of disciplines in the social sciences, such as management studies, and political science, and the natural sciences are applying SEM techniques.

As observed in Section 2, there are several component factors that are thought to complicate the direct observation of patent value. To deal with these, latent variables can be brought in and SEM allows for the modeling of the casual relationship between the observation and latent variables, whereby the factors that influence patent value can be investigated. The SEM analysis tool is the AMOS16.0J.

Firstly, the creation of the general outline of patent value was constructed from technological / social values; Technological Value (in the figure this is abbreviated to "TechValue") and Business Value as two latent variables. From this, for investigating the influence of 9 kinds of value on the observed variables, exploratory factor analysis was performed. In Figure 2 the assumptions in the early model are presented. In the figure the latent variables are elliptical, and the observation variables take on a rectangular form. $\mathrm{E}(\mathrm{X})$ is the measurement error. In 
reality it can be thought that the Business Value and Technological Value have an influence on all the variables; however in order to discriminate two latent variables, in the early model the Paper_3 variable can only be seen as related to technological value, also the Use_or5 variable only to Business Value.

In Figure $2 b$, the results of the exploratory factor analysis assumptions are presented. The number attached to pass the standardization factor in the standardized estimates, here the number shown on the right shoulder of each variable are the squared correlations coefficient. For the observation variables, including the endogenous variables, the measurement error is set. For deciding the goodness of fit in the model, several types of goodness of fit indicators were used. CMIN (Chi-square) as well as AIC (Akaike Information Criterion) and various other hypothesis testing was performed. Through the comparison of several various models in use, in particular where the number of samples is large, CMIN hypothesis testing is difficult (whereby it is easy to dispose of the model). The Goodness-of-Fit-Index is in general widely used in SEM indicators, but the models which contain missing values are difficult to use. The Comparative Fit Index (CFI) and the Root Mean Square Error of Approximation (RMSEA) is useful for this study.

In order to understand Figure $2 b$, the three variables $I f f c 5 \_t r$, Triadic, and Ln_claim, are influenced more strongly by Technology Value than Business Value. By contrast, Expct_use and Expct_bloc are influenced more strongly by Business Value. Theoretically, there are various strong influences attached to the latent variables which may not contradict the observation variables. Also in Figure 2b, Technological value has strong adverse effects on Expct_use and Expct_bloc. For this, patent possession and its "strategic significance" can have reversed technological and social implications (for high technological value patents, the objective of blocking their use to other companies may be rare) and there is no theoretical contradiction. Lic_or5 presented in Figure.2b shows that Technological Value has a stronger influence than Business Value.

From this result, while considering the theoretical integrity and adjusting the path, the indicator of values in Figure 2c employed in the SEM model are presented. Namely, with the exception of economic value evaluated by inventors (Val_dom), the Technological Value and Business Value is attached to all the other observation variables. Finally, the paths with low influence were removed and in Figure 2c Business Value and Technological Value have a fairly high correlation coefficient of 0.48. In reality, the Expct_use、Expect_bloc 、 and Lic_or5 observation variables give some influence, and there is a high possibility of this for the 3rd and $4^{\text {th }}$ latent variables. However, because this model is unduly complex and its explanation difficult, it will not be dealt with further in this section. 
Figure 2

If the causal model and the structural equation modeling are utilized, it is possible to examine the other latent factors that may indirectly influence the value of patents. With this analysis, there are assumed to be two latent variables which concern the SciTechMotive, regarding the general concept of inventor motivation such as contributing to the progress of science and technology, challenging technological issues and intellectual curiosity; and the BusinessMotive regarding the personal desire for career development or the acquisition of monetary remuneration. Furthermore, in relation to the academic sector there are two latent variables which include AcademicInf which concerns the utilization of research ideas from universities and public research institutions; and AcademicLink regarding the relationship for universities and public research institutes and the use or non-use of scientific publications. AcademicInf in a wider sense can be seen as one form of "absorptive capacity" outlined by Cohen and Levinthal in 1990.

For latent variables regarding motivation in the academic sector, there is a mutual correlation in place and the latent variables are seen to have some influence on patent values. This is the basic model for the next step analysis (Figure 3). The relationship between latent variables and observation variables are presented in Table 3.

Figure 3

Table 3

The properties of the dataset used in this research have a large number of deficiencies (missing values). As presented in Table 2, of the total variables, the valid list-wise sample is only 1,061 cases. For that reason, in order to compensate for the deficit in the assumed parameters of the SEM, I have employed Full Information Maximum Likelihood Estimation (from hereon abbreviated as FIML).

The FIML estimation method uses continuous variables assuming a multi-variate normal distribution for the estimators; for the parameter distribution there is a Gaussian distribution with high robustness (Arbuckle 2007). If the ordinal variables, and in particular the number of categories are small then there can be a large deviation from a Gaussian distribution, and also from the Maximum Likelihood Estimation. In this case the AMOS 16.0 as an alternative to the FIML, Bayesian - Markov Chain Monte Carlo estimators are used in the SEM. Therefore, to check the validity of the results in the FIML, recoding of the ordinal variables and the estimation using Bayesian-MCMC estimation was used. 
As observed from the variables in the preceding section, a basic cross tabulation will be performed. In Figure 4 triadic patents and non-triadic patents are totaled against inventor estimates of the patent value $\left(V a l \_d o m\right)$. To compare the distributions of the triadic and non-triadic patents on the right side (where the value is high), for triadic patents (where there a large family size is held) certainly it can be assumed that there is a relationship with patent value indicators. However, it is useful to observe the value distribution for the non-triadic patents According to the above definition, within the Top $10 \%$ the expected value is $10 \%$, for the Top $25 \%$ (excluding the Top 10\%), the expected value is $15 \%$, for the Top $50 \%$ the expected value is $50 \%$. In practice (excluding the top 25\%) the component comparative ratio for the expected value is greater than the expected value, for the lower $50 \%$ the total component comparative ratio is lower than the expected value. In general, this is the high estimated value by the inventor (inventor bias). Regarding this point, from the viewpoint of the technological value and the business value it is worthwhile considering this point further below.

(Figure 4)

Furthermore, observing the variable for patent value, simple multi-regression analysis will be performed. In Table 4, the totals are presented on a psychological scale for continuous variables with Val_dom as the explanatory variable for OLS regression analysis. For these variables, the number of valid list-wise observations is 2,039 cases. Looking at the results, and excluding Ln_claim, the variable coefficient has $1 \%$ significance, and the variance inflation factor value can be judged to not have too much multi-colinearity. The R-square value is 0.124 which is not particularly high. Also, the coefficient for Expct_bloc is negative, suggesting that the strategic value of patents (in contrast to expectations) and inventor recognition of economic value is on the whole holding a negative relationship.

Table 4

In Table 5 the results of the ordered probit regression are presented. To review this result, category 3 and category 4 for Val_dom (higher rank 25\%; and 10\%) is not significant. Ln_claim (the only continuous variable) is barely significant at the $10 \%$ level, but the reversed sign suggests a negative relationship. Also, identically the OLS results for one section category of Expct_bloc and Val_dom have a reverse threshold and a negative symbol.

From this multiple regression method various indicators on patents and the relationship to their economic value can be obtain and estimated. However, for estimating the patent values 
various complex factors exist and to perceive the relationships may not be entirely possible.

Table 5

\section{(2) Analysis of the model}

Next, as was stated earlier, based on the whole constructed model in Figure 2, FIML estimation was used. In the early stages of the model the assumed results were not valid, so in Figure 5 the revised estimated results have been presented. Restricting our judgment to CFI and RMSEA, the goodness-of-fit for this model is not very high; however, with considering that the variables have been ordinal categories as a large part of the data, these CFI and RMSEA values could be judged as a acceptable level (the complete list for estimated parameters are in the appendix).

In addition, based on the model, Val_dom's squared correlation coefficient is 0.25 , as presented in Figure 2c. In Figure 5 it is 0.3 , and much greater than the multiple regression analysis coefficient of determination of 0.13 and 0.15 (Tables 4 and 5). On this point as well, the model that incorporates latent variables works well, and it can be considered that latent variables have been shown to have indirect validity.

Table 5.

In Table 6, for each of the path standardized coefficients, FIML estimates and Bayesian estimates were obtained and compared. As anticipated, concerning the variables that have skewed distribution (Num_SL and AcNW etc.), some degree of separation discrepancy can be observed, however, in general there is a coincidence and no contradictions can be confirmed; from hereon on the basis of the FIML estimation results debate will continue.

Table 6

Looking at the coefficients for the estimated results of the FIML method, for inventors the recognized value for patents (Val_dom) it is better explained by the technological value/social value than the business value. This is the case where the inventor evaluates the "economic value of the patent", the technological value is considered slightly more seriously. Regarding the actual condition of "inventor bias", unconsciously there is a greatest common denominator on inventor responses on the technological value and business value, with the production of an aggregation fallacy. It had been reported based on the PatVal-EU survey 
that inventors' evaluation on a "monetary value" of patent also had a tendency for a high evaluation (see section 2). These inventor biases are considered to be caused by the latent potential and value (shadow price) of the invention.

In this model, the correlation between the error terms for the technological value and business value (eS and eP) is seen to be high. It implies that the $3^{\text {rd }}$ (and the $4^{\text {th }}$ ) factor should exist behind the scene. Those are factor(s) not included in this model, for instance, the attributes of inventors and their knowledge and experience, company strategy, project management, and the surrounding external environment. For the RIETI survey results, many potentially useful data is yet to be remained, and this is an issue for later analysis. In particular, for squared multiple correlation coefficient for business value in the model is only 0.12 , with little explanatory power. Therefore, in order to enhance the explanatory power of business value, the management side should be incorporated in the future survey of patent value, or existing kinds of data from the results of the study could be joined together for the analysis.

According to this model, academic links has a strong positive influence on technological value, but in contrast, it has a negative influence on the business value. For companies it is suggested that university-industry-government links have two sides which can be both pluses and minuses. For this analysis, the observation and use of variables on Academic Links, the synthesis variable $(A c N W)$ and the sequential categories there are issues surrounding linearities; it is considered that with $A c N W$ and Num_SL the variable of analysis is extremely biased; there is still scope for further investigation from hereon.

From the result of this analysis, it is suggested that SciTechMotive has a direct positive effect on technological value as well as Business Value. To begin with, there is a debate that for researchers' intellectual curiosity stimulates a motivational incentive, but it is also possible that researchers hold a high SciTechMotive for high value inventions. On the other hand, PrivateMotive such as financial or status does not have any direct relationship with, technological value or business value and it should be a latent co-variant.

The use of information by inventors in the model through AcademicInf does not have a direct effect on TechnologicalValue and BusinessValue. However, for AcademicInf there are two types of motives for AcademicLink which are widely correlated. In this model, only academic information use has been considered, but for the RIETI survey the patent literature, company literature, and exhibitions also exist, other information for absorptive capacity can be investigated and incorporated into later issues.

\section{(3) Analysis by Field}

In this section, the results for parameter estimation by technological field with the same 
model (same structure configural invariance) will be presented. In this paper the following technological fields were included:

$\begin{array}{ll}\text { Chem: } & \text { Chemicals } \\ \text { Drug: } & \text { Drugs and Medicals } \\ \text { Comp: } & \text { Computers and Communications } \\ \text { Elec: } & \text { Electrical and Electronic } \\ \text { Mech: } & \text { Mechanical } \\ \text { Others: } & \text { All other fields (including software etc.) }\end{array}$

In Table 7 analysis results for the estimated coefficients for the technology fields are listed. To compare the Technological Value and Business Value on Val_dom, for Chem and Drug there is a large influence from Business Value, with the other fields being different. For this, the patents in these technological fields are largely substance patents, and they are appropriate for value appropriation of the invention. So, there is perhaps a relationship where the process for validity of the patent is high (Goto and Nagata 2002). Also, for Chem and Drug (in particular for Drug) the coefficient for Triadic has a small value. It is likely for these fields, by the way of recent PCT developments, international applications have increased (Japan Patent Office Annual Report 2007). To some degree for important inventions, triadic applications have possibly become the norm.

Furthermore, for Drug and other fields Technological Value has a large influence on Paper_3. For this field there is a trend for important technological developments to be published in the literature. Also for Chem, in comparison to other fields the contribution of Ln_claim is small. The cause for this is that a characteristic of substantive patents take the form of description of the structure of constitutional isomer and tend to have a large number of claims, and also for PCT applications, there is a tendency to include many claims in order only to get the priority date. In comparison to other fields, the Technological Value for Drug has only a small influence on $I \_f c 5 \_t r$. For inventor forward citation in general is seemed as the importance of technology indicators in such fields that a cumulative path plays an important roll. But for medical supplies it is suggested that the creative originality is more important than the cumulative progress.

\section{Table 7}

For the Comp field, the indicator for own-use by companies of patents, Use_or5 and the indicator for licensing, Lic_or5 both share a coefficient for Business Value which does not possess much meaning. By contrast, Expct_bloc is seen to possess significant meaning. For this, for patents in the Comp field, business value exists in a large part strategic blocking 
rather than technology use, in the so-called "patent thicket" (Kash and Kingston 2001), which is one interpretation. Also, Lic_or5 has low importance for Drug and Elec.

In comparison to other fields, for Mech, Num_SL has low importance. Within this field the automobile industry and other representative Japanese industries produce a large number of patents; within this field the academic linkage is small and the role of the scientific literature as a source for knowledge may contribute only a small amount.

Throughout the Table 7, both positive and negative influences which AcademicLink has on Technological Value and Business Value can be robustly observed. As stated before, for those that possess university-industry-government linkages there are two sides to this relationship and it may be suggested this has universal applicability.

Drug is unlike some other fields, from SciTech_motive to TechnologicalValue there is generally no influence. The cause for this could be understood that in this field science and industry are relatively proximate so it is thought that scientific motivation is an important requirement for invention. On the other hand for Chem and Comp the SciTech_Motive has less influence on BusinessValue than on TechnologicalValue.

For Drug, Mot_sci and also for Chem, InConc_ac dispersion is negative. The negative distribution tells us that this model does not fit well in those fields. So these results need to be interpreted with great care.

\section{Implications}

Employing the use of Structural Equation Modeling methods, the structure of the latent factors which influence patent values have been modeled. This model includes two latent factors; "technological value" and "business value" as the basis for a concept of patent values. This model, although a bit complicated, had a high goodness of fit to the observed data than a plain multiple regression model.

The implications suggested by this structural model are as follows: 1) the motivations for science and technology by researchers (contributing to the progress of science and technology and overcoming challenges and issues) are not only to raise the technological value of inventions; but also raising the business value. This suggests that plans for human resources involved in corporate R\&D should be nurtured and given consideration. For these individuals, how should motivation for science and technology be given through some sort of incentives? Further examination is necessary in regard to this point; however, for employees participation in scientific meetings with the research community may provide intellectual stimulation, and researchers might have higher motivations if they can select technological issues to be tackled by themselves. 
The second implication from this structural model is the private motivation held by researchers (financial remuneration and the desire for promotion); for companies it is suggested that the direct elevation of the business value is difficult. On this point, for instance Article 35 in the Japanese Patent Law has established that "the suitable compensation" for invention and incentive should be available, but the features of this have been questioned (equally, awareness of this issue is discussed in Owan and Nagaoka 2008). However, the results of this analysis at the same time suggest that the personal motivation of researchers and science and technology motivations and information absorption, or "Absorptive Capacity", have strongly positive relationships. Namely, a strong private motivation tends to accompany the strong technological motivation, and also accompanies the tendency for information absorption and its applicability. Conversely, the management, systems or customs which decrease private motivation may also perhaps decrease motivations for science and technology motivation. Or, would it also be possible for indicators on heightened personal motivation; that is, the motivation towards science and technology and the appointment of high level personnel? Whether or not the direction of these causal relations and necessary/sufficient condition is formed or not, requires further examination in the future.

The third implication from this structural model is that the influence of industry-university-government cooperation for the value of general patents has two characteristics which are "plus" and "minus". Namely, university-business cooperation operates in the direction in which the technological value of an invention rises, but, on the other hand it is suggested that value with respect to business is decreased. When viewed from the side business perspective, a reason why patents from university-industry-government cooperative activities have only moderate value is that for rights (rights that are shared with universities on the basis of public funding) there are complications. For instance, for the business value of patents one component is the "blocking" potential; for corporate strategy a reason is that patent possession can be self enforced and licensing not performed giving the patent value. For joint patents with universities, on the university side as a general rule the optimum putting into practice of the patent is sought; there are times when confrontation may emerge. Also, for universities and public research institutes, for the intellectual property rights from collaborative research performed through university-industry-government relations, the non-exclusive execution rights and the requests for compensation for non-execution compensation are large. The desire for restrictions regarding the handling of research results on the industry side are many and towards the partner, the direction in which licensing limitations are eased or modified, part of public organizations are in the process of doing (Advanced Industrial Research Institute 2007). In addition, as Nagaoka and Walsh (2008) have observed, many inventions produced from university-industry cooperation are at a fundamental level, and direct connection with business is difficult and it is thought that value 
with respect to business is relatively low. Furthermore, as this analysis has shown, the influence of industry-university-government cooperation differs largely depending upon the technical field.

In the second section of this paper, drawing the analytical results for the PatVa-EU survey, the direct influence of the scope and attributes of the organizational affiliation of the inventor on the monetary value of patents were not able to be observed. Furthermore, as in the preceding paragraph, within this model only the framework variables, in particular the business value of patents have not been clearly explained and perhaps the age of inventors, academic background and other attributes, such as the size of their organization, projects etc. have a large number of exogenous and endogenous variables which do not include explanatory variables (included in the error term). As stated earlier, if through the method modeling the influence of indirect factors can be elucidated, and consideration of high value patents and their connection with corporate strategy and policy support would be useful.

\section{Acknowledgements}

This data analysis and research outline benefitted from valuable suggestions and advice from Sadao Nagaoka, the chief editor of the RIETI survey; Tsukada Naotoshiof Hitotsubashi University Doctoral course assisted with the raw data operations; Naito Yuusuke from the Alife Laboratory Inc. is deeply thanked for his assistance. Also, Professor Wada Tetsuo from Gakushuin University and Professor Owan Hideo from Aoyama Gakuin University contributed suggestions at research meetings and workshops. Professor John Walsh (Georgia Institute of Technology), Professor Bronwyn Hall (UC Berkeley), Professor Dietmar Harhoff (Munich University), Professor Alfonso Gambardella (Bocconi University) are gratefully thanked for providing suggestions during workshops and individual discussion. The author would like to extend considerable thanks to Professor Goto Akira from the National Graduate Institute for Policy Studies for providing the impetus for this research. To hear valuable comments and ideas at workshops and research meetings, the author would like to deeply thank Fujita Masahisa, the Director of RIETI as well as the various people associated with RIETI for their support and assistance.

\section{References}

Arbuckle, J., 2007. AMOS 16.0 Statistical Software. Amos Development Corporation, Spring House, PA. 
Arora and Ceccagnoli, (2006), "Estimating a system of simultaneous equations where the patenting and licensing decisions are jointly determined by firm and industry characteristics”. Management Science, Feb. 2006.

Don E Kash and William Kingston, Patents in a world of complex technologies, Science and Public Policy, volume 28, number 1, February 2001, pages 11-22.

Guellec, Dominique \& Pottelsberghe de la Potterie, Bruno v., 2000. "Applications, grants and the value of patent," Economics Letters, Elsevier, vol. 69(1), pages 109-114

Hall, B. H., Jaffe, A. B. and Trajtenberg, M. (2002) "The NBER Patent-Citation Data File: Lessons, Insights, and Methodological Tools.” in A. B. Jaffe and M. Trajtenberg eds., Patents, Citations \& Innovations: A Window of the Knowledge Economy, Cambridge, MA: MIT Press.

Hall, B. H., A. Jaffe, and M. Trajtenberg (2005) "Market Value and Patent Citations," RAND Journal of Economics 36, 16-38.

Harhoff, D., F. M. Scherer, and K. Vopel (2003) "Citations, Family Size, Opposition and the Value of Patent Rights," Research Policy 32, 1343-63.

Jean O. Lanjouw \& Mark Schankerman, 1997. "Stylized Facts of Patent Litigation: Value, Scope and Ownership," NBER Working Papers 6297, National Bureau of Economic Research

Joreskog, K. G., 1978, Structural analysis of covariance and correlation matrices, Psychometrika, 43, 443-477.

Joshua Lerner, "The Importance of Patent Scope: An Empirical Analysis", The RAND Journal of Economics, Vol. 25, No. 2. (Summer, 1994), pp. 319-333.

Lanjouw, J. O. and M. Schankerman (2004b) "Patent Quality and Research Productivity: Measuring Innovation with Multiple Indicators," Economic Journal 114, 441-465.

Lee, S. Y., 2007. Structural equation modeling: A Bayesian approach. Chichester, England: Wiley.

Nagaoka and Walsh, 2008, Inventions and the innovation processes in Japan and US: Highlights from the US-Japan Inventor Survey, RIETI Discussion Paper, Forthcomming.

Narin, F., K. S. Hamilton, and D. Olivastro (1997) "The Increasing Linkage between US Technology and Public Science," Research Policy 26, 317-330.

Owan and Nagaoka, 2008, Intrinsic and Extrinsic Motivation for Inventors, RIETI Discussion Paper, Forthcomming.

Office of Technology Assessment and Forecast, US Department of Commerce, Patent, and Trademark Office. Sixth Report. Washington DC.; US Government Printing Office, 1976

Paola Giuri, et. al, (2007), "Inventors and invention processes in Europe: Results from the PatVal-EU survey", Research policy, Vol. 36, Issue 8, 1107-1127 
PatVal-EU, 2005. The value of the European patents: evidence from a survey of European Inventors. Final Report of the PatVal-EU Project, DG Science \& Technology, European Commision, Contract No. HPV2-CT-2001-00013, Brussels.

Sampat, B. N. Determinants of Patent Quality: An Empirical Analysis (2005), Columbia University Working Paper.

Schmookler,Jacob, 1966, "Invention and Economic Growth," Harvard University Press.

Study on evaluating the knowledge economy - What are patents actually worth? - , EC technical report MARKT/2004/09/E, Lot 1, May, 2005

Study on evaluating the knowledge economy - What are patents actually worth? - , EC technical report MARKT/2004/09/E, Lot 2, July, 2006

Trajtenberg, Manuel. "A Penny for Your Quates; Patent Citations and the Value of Innovations." RAND Journal of Economics 21, no. 1 (1990): 172-87

Wesley M. Cohen and Daniel A. Levinthal, Absorptive Capacity: A New Perspective on Learning and Innovation, Administrative Science Quarterly, Vol. 35, No. 1, (Mar., 1990), pp. 128-152

Zvi Griliches, "Patent Statistics as Economic Indicators: A Survey", Journal of Economic Literature, Vol. 28, No. 4. (Dec., 1990), pp. 1661-1707.

Nagaoka, S., Tsukuda, N., (2007), "Japan's Innovation Process as Viewed by Inventors: Outline Results of RIETI Inventors Survey", RIETI Discussion Paper Series 07-J-046、 2007

AIST (2007), "Policy for Mitigation of Practical Use of Joint Intellectual Property Rights", Advanced Industrial Science and Technology, Press Release, 30 August, available at:

http://www.aist.go.jp/aist_j/press_release/pr2007/pr20070830/pr20070830.html

JPO (2007), Japan Patent Office Annual Report, Japan Patent Office, Japan Invention Committee, July

Goto, A., and Nagata, A., (1997), Technological opportunities and appropriating the returns from innovation: Comparison of survey results from Japan and the U.S., National Institute of Science and Technology Policy, NISTEP Report No.48.

Tamada, S., (2005), The Source of Technological Innovation: Science Linkage from the Viewpoint of Industrial Technology Policy, RIETI Policy Analysis Paper No.5

Suzuki, J., Tamada, S., Naito,Y., Motohashi, K., and Goto, A., (2008), "Patent Citations in Japan - Database Construction for Inventor Citations and Examiner Citations", presented in the Conference on Patent Statistics for Decision Makers, Organized by EPO and OECD. 


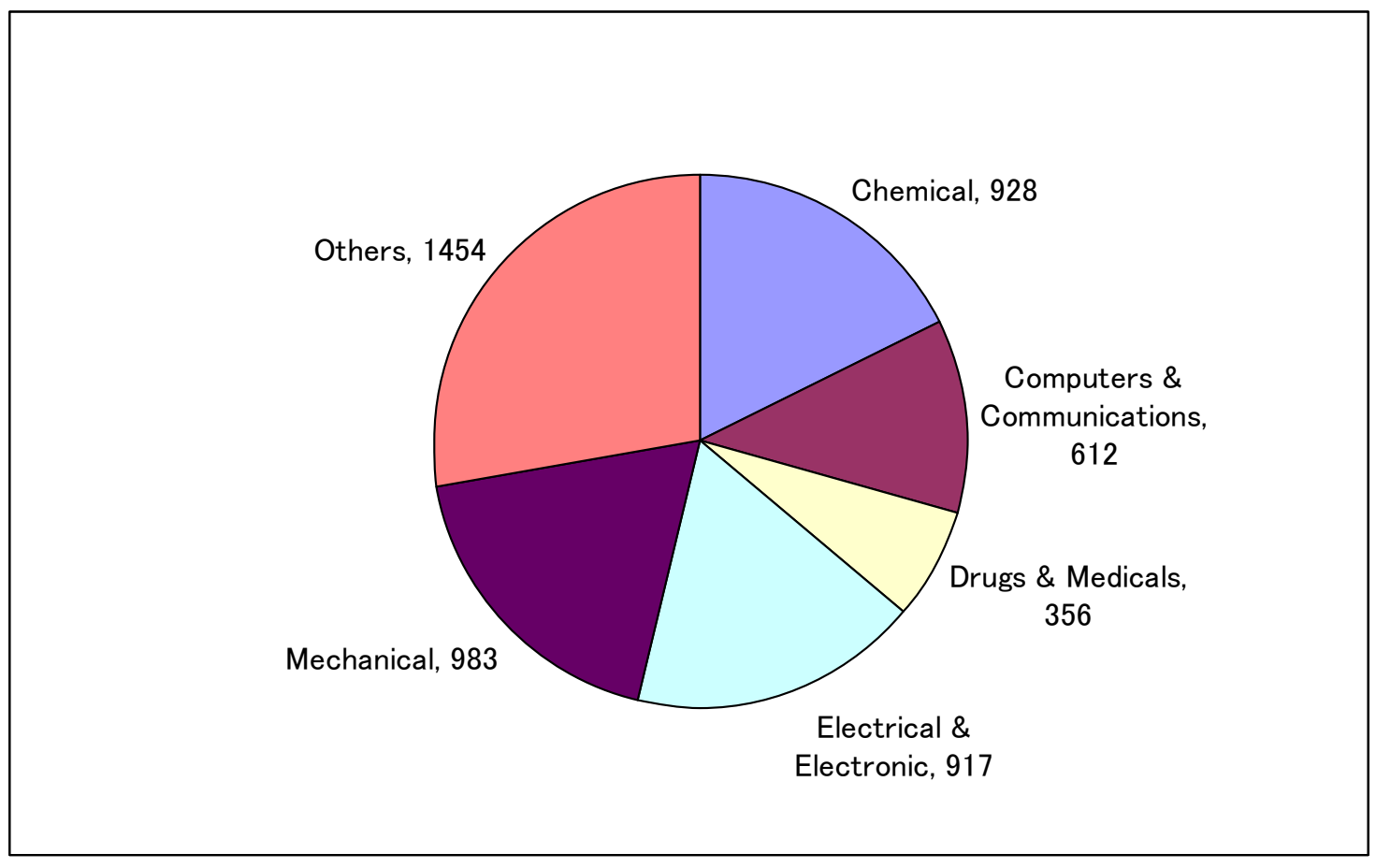

Figure.1 Technological field distribution in the RIETI survey sample 

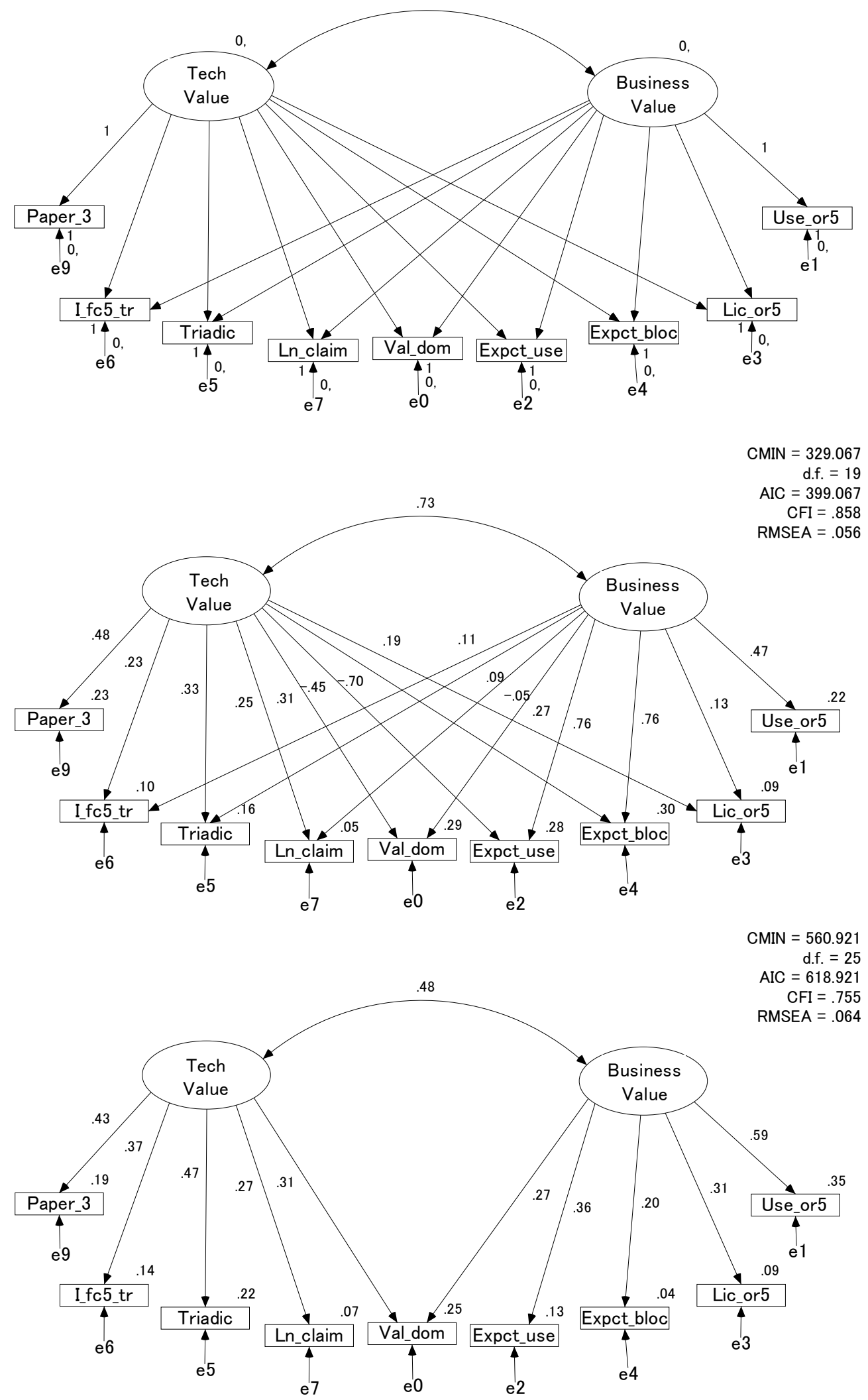

Figure.2a(upper)、2b (middle)、2c (lower) Estimated Results of Factor Analysis of patent value variables 


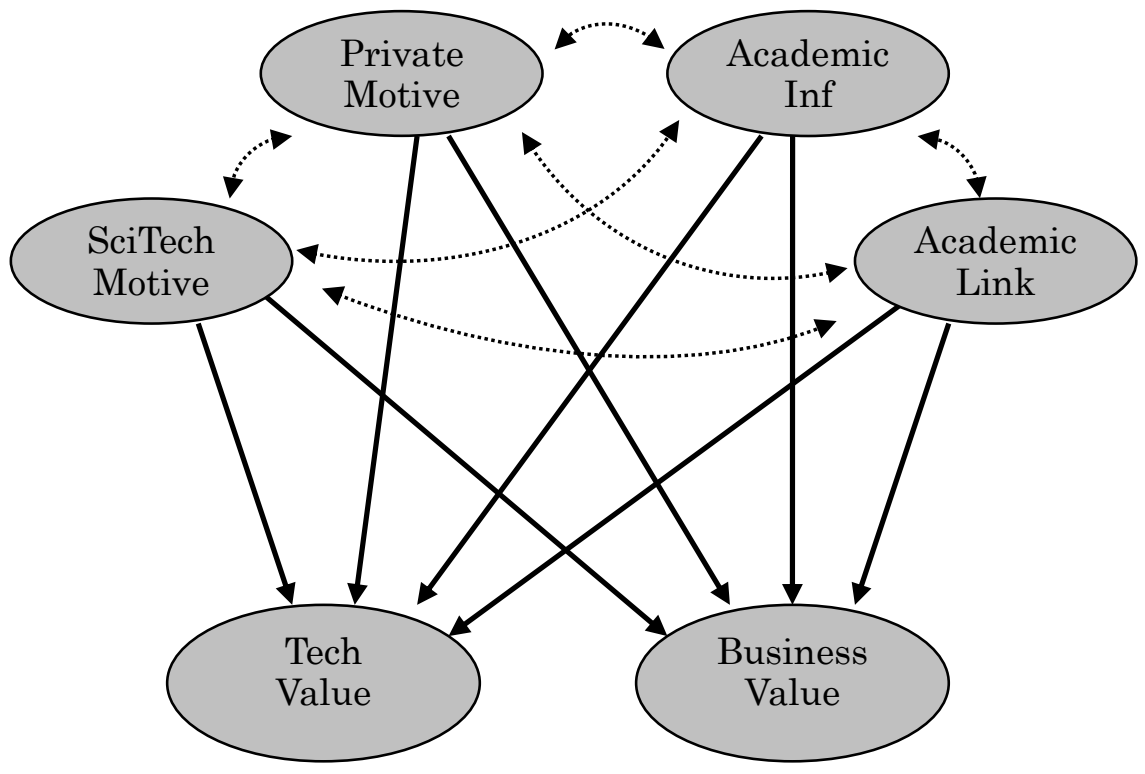

Figure.3 Basic Model of Correlation and causal relationship with Latent variables

\begin{tabular}{l|rrrrrrr|r} 
& non-triadic & $\%$ & triadic & $\%$ & VIP & 要 $\%$ & sub total \\
\cline { 2 - 8 } & $382(39.1)$ & $675(25.2)$ & $10(13.7)$ & 1,067 \\
Top 50\% (excluding top 25\%) & $376(38.4)$ & $1,045(39.0)$ & $23(31.5)$ & 1,444 \\
Top 25\% (excluding top 10\%) & $149(15.2)$ & $671(25.0)$ & $22(30.1)$ & 842 \\
& $71(7.3)$ & $288(10.8)$ & $18(24.7)$ & 377 \\
Valid Total 10\% & 978 & 100 & 2,679 & 100 & 73 & 100 & 3,730 \\
Missing Val_dom & 523 & & 979 & & 18 & & 1,520 \\
Grand Total (Year after 1995) & 1,501 & & 3,658 & & 91 & & 5,250
\end{tabular}
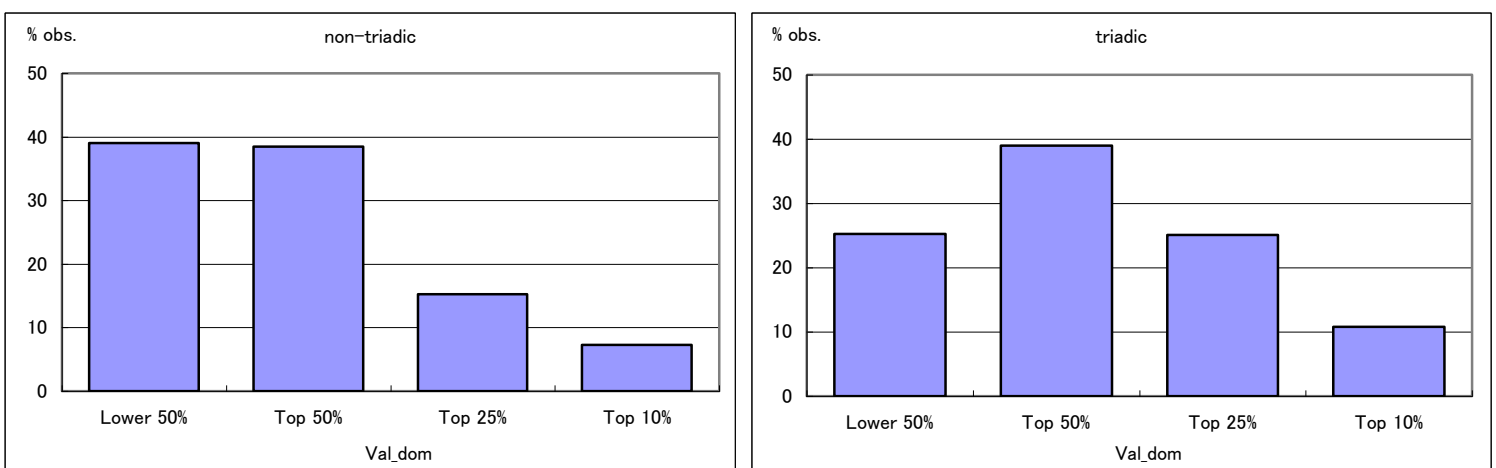

Figre.4 Cross tabulation on Patent Value and Triadic Patents 


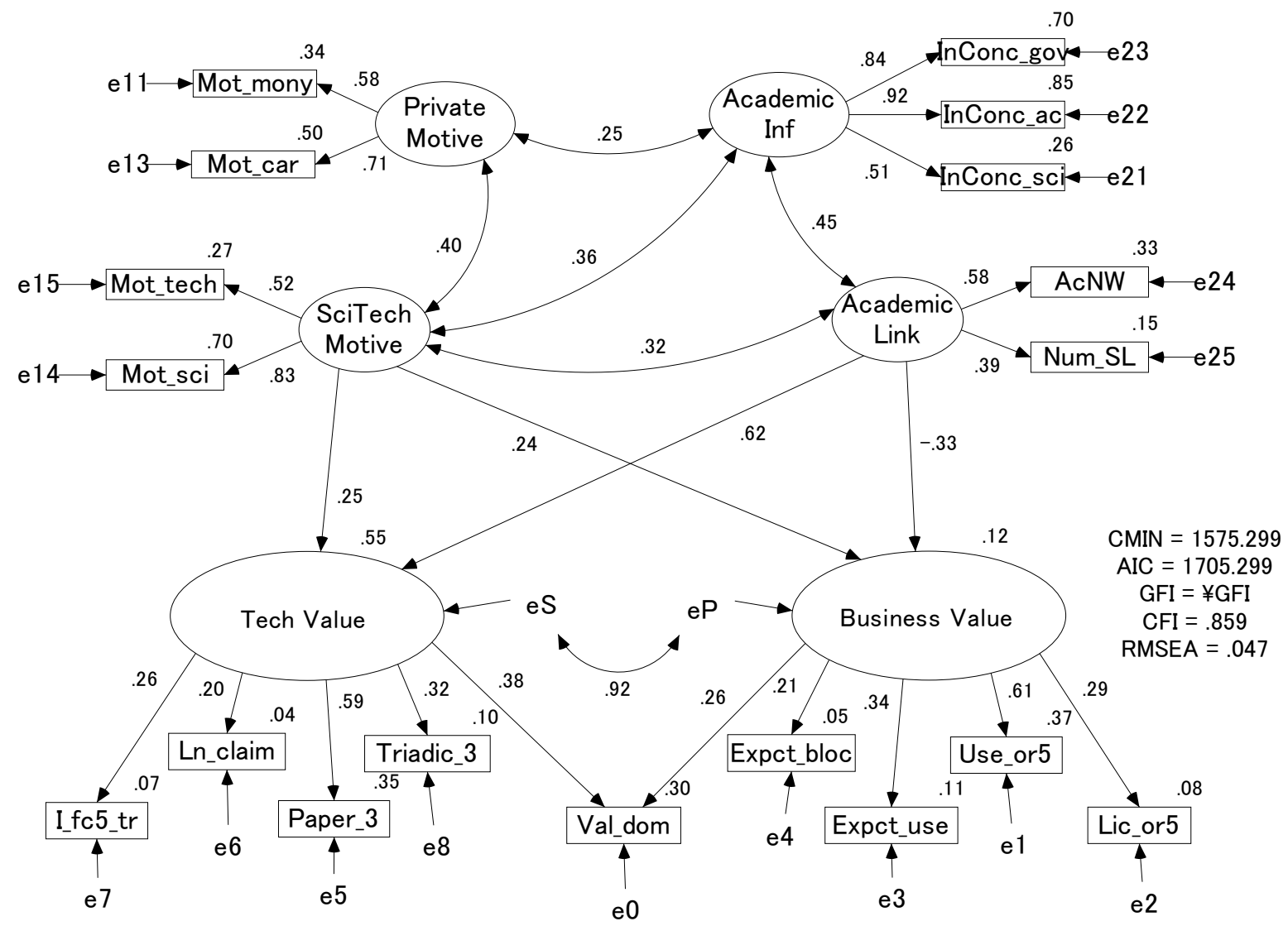

Figure.5 Construction of Patent Evaluation Model 
Table.1 Definition of Variables: Categories and Data source

\begin{tabular}{|c|c|c|c|c|}
\hline $\begin{array}{l}\text { Variable } \\
\text { Name }\end{array}$ & Outline & Variable Type & Category/Definition & Data source \\
\hline Val_dom & $\begin{array}{l}\text { Economic value of domestic } \\
\text { patents at same time and } \\
\text { same field }\end{array}$ & Ordinal & $\begin{array}{l}1: \text { Lower } 50 \% \\
2: \text { Upper } 50 \% \text { (with the exception of categories } 2 \\
\text { and } 4 \text { ) } \\
3: \text { Upper } 25 \% \text { (with the exception of category } 4 \text { ) } \\
4: \text { Upper end } 10 \%\end{array}$ & Survey Q6.11 \\
\hline Triadic_3 & $\begin{array}{l}\text { Existence of triadic patents, } \\
\text { standards or important } \\
\text { patents }\end{array}$ & $\begin{array}{l}\text { Ordinal } \\
\text { (Composite) }\end{array}$ & $\begin{array}{l}0: \text { No triadic application } \\
1: \text { Triadic application (with the exception of } \\
\text { category 2) } \\
2: \text { Standard/important patent }\end{array}$ & $\begin{array}{l}\text { Survey } \\
\text { sample } \\
\text { attribute }\end{array}$ \\
\hline Use_or5 & $\begin{array}{l}\text { Existence of use within the } \\
\text { company }\end{array}$ & $\begin{array}{l}\text { Ordinal } \\
\text { (Composite) }\end{array}$ & $\begin{array}{l}0: \text { No use within company (with the exception of } \\
\text { categories } 1 \text { and } 2 \text { ) } \\
1: \text { No use within company (for the purpose of } \\
\text { business elevation) } \\
2: \text { No use within company (possession of strategic } \\
\text { value) } \\
3: \text { Use within company (with the exception of } \\
\text { category } 4 \text { ) } \\
4: \text { Establishment of new company }\end{array}$ & $\begin{array}{l}\text { Survey } \\
Q 6.3+Q 6.7+Q \\
6.8\end{array}$ \\
\hline Lic_or5 & $\begin{array}{l}\text { Existence of licensing to } \\
\text { another party }\end{array}$ & $\begin{array}{l}\text { Ordinal } \\
\text { (Composite) }\end{array}$ & $\begin{array}{l}0 \text { : No licensing (with the exception of categories } 1 \\
\text { and 2) } \\
1 \text { : No licensing (for business elevation) } \\
2 \text { : No licensing (possession of strategic value) } \\
3 \text { : Licensing (with the exception of category 4) } \\
4 \text { : Licensing to various companies }\end{array}$ & $\begin{array}{l}\text { Survey } \\
\text { Q6.6+Q6.8 }\end{array}$ \\
\hline Paper_3 & $\begin{array}{l}\text { Existence of scientific } \\
\text { publications }\end{array}$ & $\begin{array}{l}\text { Ordinal } \\
\text { (Composite) }\end{array}$ & $\begin{array}{l}0: \text { Not published (technological level was low) } \\
1: \text { Not published } \\
2: \text { Published as a paper }\end{array}$ & $\begin{array}{l}\text { Survey } \\
\text { Q6.9+Q6.8 }\end{array}$ \\
\hline Ln_claim & Patent application scope & Scale & $\begin{array}{l}\text { Number of claims at time of application (natural } \\
\text { logarithm) }\end{array}$ & $\begin{array}{l}\text { Patent } \\
\text { Statistics }\end{array}$ \\
\hline I_fc5_tr & $\begin{array}{l}\text { Number of citations received } \\
\text { within } 5 \text { years of patent } \\
\text { acquisition }\end{array}$ & Ordinal & $\begin{array}{l}0: \text { None } \\
1: 1 \text { case } \\
2: \text { over } 2 \text { cases }\end{array}$ & $\begin{array}{l}\text { Patent } \\
\text { Statistics }\end{array}$ \\
\hline Expct_bloc & Expected use: within firm & Ordinal & $\begin{array}{l}1: \text { Totally unimportant } \\
2: \text { Not Important } \\
3: \text { Can' t say } \\
4: \text { Important } \\
5: \text { Very Important }\end{array}$ & Survey Q6.2 \\
\hline Mot_sci & $\begin{array}{l}\text { Motivation: Contribute to } \\
\text { science and technology } \\
\text { Motivation: address }\end{array}$ & \multirow{4}{*}{ Ordinal } & \multirow{4}{*}{$\begin{array}{l}1: \text { Totally unimportant } \\
2: \text { Not Important } \\
3: \text { Can't say } \\
4: \text { Important } \\
5: \text { Very Important }\end{array}$} & \multirow{4}{*}{ Survey Q5.1 } \\
\hline Mot_tech & $\begin{array}{l}\text { scientific challenges } \\
\text { Motivation: Career }\end{array}$ & & & \\
\hline Mot_car & $\begin{array}{l}\text { Motivation: Career } \\
\text { development }\end{array}$ & & & \\
\hline Mot_mony & $\begin{array}{l}\text { Motivation: financial } \\
\text { remuneration }\end{array}$ & & & \\
\hline AcNW & $\begin{array}{l}\text { Relations with public } \\
\text { research laboratory }\end{array}$ & $\begin{array}{l}\text { Ordinal } \\
\text { (Composite) }\end{array}$ & $\begin{array}{l}\text { Coinv_ac_d(Existence or not of Collaborative } \\
\text { Invention with University Researcher; } 2 \text { values); } \\
\text { Coop_ac_d (existence or not of university research } \\
\text { collaboration: } 2 \text { values); Fund_gov_d(receipt or not } \\
\text { of public funds: } 2 \text { values) }\end{array}$ & $\begin{array}{l}\text { Survey } \\
\text { Q4.9+Q10+Q1 } \\
7\end{array}$ \\
\hline Num_SL & $\begin{array}{l}\text { Science Linkage (number of } \\
\text { citations to scientific } \\
\text { papers within the patent) }\end{array}$ & Ordinal & $\begin{array}{l}0: \text { None } \\
1: 1 \text { case } \\
2:>2\end{array}$ & $\begin{array}{l}\text { Patent } \\
\text { Statistics }\end{array}$ \\
\hline
\end{tabular}


Source for Research

Conception: Scientific publications

Source for Research

InConc_ac

Conception: university

Source for Research

Conception: public research

InConc_gov
0 : Do not use

1: Totally unimportant

2: Not important

3: Can't say

4: Important

5: Very important
Survey Q4.12 
Table.2 Descriptive Statistics of Observed Variables

\begin{tabular}{|c|c|c|c|c|c|c|c|}
\hline & Cases & Minimum & Maximum & Average & $\begin{array}{c}\text { Standard } \\
\text { Error }\end{array}$ & Skewness & Kurtosis \\
\hline Val_dom & 3,730 & 1 & 4 & 2.142 & 0.947 & 0.430 & -0.740 \\
\hline Triadic_3 & 5,250 & 0 & 2 & 0.731 & 0.481 & -0.567 & -0.559 \\
\hline Use_or5 & 5,130 & 0 & 4 & 1.975 & 1.280 & -0.539 & -1.264 \\
\hline Lic_or5 & 5,010 & 0 & 4 & 1.194 & 1.412 & 0.751 & -0.836 \\
\hline Paper_3 & 5,143 & 0 & 2 & 1.130 & 0.457 & 0.487 & 1.137 \\
\hline Ln_claim & 5,250 & 0 & 5.170 & 1.683 & 0.843 & -0.091 & -0.012 \\
\hline I_fc5_tr & 3,845 & 0 & 2 & 0.515 & 0.791 & 1.089 & -0.525 \\
\hline Expct_use & 3,865 & 1 & 5 & 4.177 & 0.924 & -1.403 & 2.162 \\
\hline Expct_bloc & 3,819 & 1 & 5 & 3.745 & 0.999 & -0.948 & 0.715 \\
\hline Mot_sci & 5,116 & 1 & 5 & 3.569 & 1.064 & -0.719 & 0.081 \\
\hline Mot_tech & 5,164 & 1 & 5 & 4.244 & 0.793 & -1.458 & 3.465 \\
\hline Mot_car & 5,081 & 1 & 5 & 2.833 & 1.084 & -0.162 & -0.714 \\
\hline Mot_mony & 5,082 & 1 & 5 & 2.734 & 1.054 & -0.107 & -0.656 \\
\hline AcNW & 5,128 & 0 & 3 & 0.137 & 0.436 & 3.571 & 13.568 \\
\hline Num_SL & 5,250 & 0 & 2 & 0.193 & 0.544 & 2.707 & 5.832 \\
\hline InConc_sci & 4,060 & 1 & 5 & 3.723 & 1.033 & -0.900 & 0.413 \\
\hline InConc_ac & 2,795 & 1 & 5 & 2.718 & 1.125 & 0.015 & -0.819 \\
\hline InConc_gov & 2,670 & 1 & 5 & 2.597 & 1.068 & 0.002 & -0.821 \\
\hline
\end{tabular}


Table.3 Relationship between Latent variables and Observed Variables

\begin{tabular}{|c|c|c|}
\hline $\begin{array}{c}\text { Composition } \\
\text { Outline }\end{array}$ & Latent Variable & $\begin{array}{c}\text { Observation } \\
\text { Variable }\end{array}$ \\
\hline \multirow{9}{*}{ Patent Value } & \multirow{4}{*}{ Tech Value } & Paper_3 \\
\hline & & Ln_claim \\
\hline & & I_fc5_tr \\
\hline & & Triadic_3 \\
\hline & Tech \& Business Value & Val_dom \\
\hline & \multirow{4}{*}{ Business Value } & Use_or5 \\
\hline & & Lic_or5 \\
\hline & & Expct_use \\
\hline & & Expct_bloc \\
\hline \multirow{4}{*}{ Inventor Motivation } & \multirow{2}{*}{ SciTech Motive } & Mot_sci \\
\hline & & Mot_tech \\
\hline & \multirow{2}{*}{ Private Motive } & Mot_car \\
\hline & & Mot_mony \\
\hline \multirow{5}{*}{$\begin{array}{l}\text { Relations with the } \\
\text { Academic Sector }\end{array}$} & \multirow{2}{*}{ Academic Link } & AcNW \\
\hline & & Num_SL \\
\hline & \multirow{3}{*}{ Academic Inf } & InConc_sci \\
\hline & & InConc_ac \\
\hline & & InConc_gov \\
\hline
\end{tabular}

Table.4 Results of the OLS Regression Analysis on Patent Value

$$
\begin{array}{rc}
\text { Model-1 OLS estimation } \\
\text { Dependent variable: } & \text { Val_dom } \\
\text { Observations } & 2,039 \\
\text { R squared } & 0.127 \\
\text { Adj. R squared } & 0.124
\end{array}
$$

\begin{tabular}{lrll} 
Variables & Coefficient & $\mathrm{t}$-value & VIF \\
\hline \hline (Constant) & 0.853 & $(6.576) * * *$ \\
Use_or5 & 0.107 & $(6.113) * * *$ & 1.080 \\
Lic_or5 & 0.077 & $(5.669) * * *$ & 1.032 \\
Triadic_3 & 0.124 & $(2.703) * * *$ & 1.078 \\
Paper_3 & 0.384 & $(8.528) * * *$ & 1.057 \\
Ln_claim & $0.039(1.635)$ & 1.048 \\
I_fc5_tr & $0.091(3.701) * * *$ & 1.070 \\
Expct_use & $0.133(5.733) * * *$ & 1.105 \\
Expct_bloc & $-0.057(-2.80) * * *$ & 1.088 \\
\hline \multicolumn{4}{c}{$* * *: 1 \%$ significant }
\end{tabular}

Table.5 Results of Ordered Probit Analysis of Patent Value 
Model-2 Ordered Probit estimation

Observations 2,039

-2Log likelihood 4555.7

Chi-squred (d.f.) 333.3(23)

Pseudo R squared $\quad 0.151$

Variables Thresholds Coefficient Wald

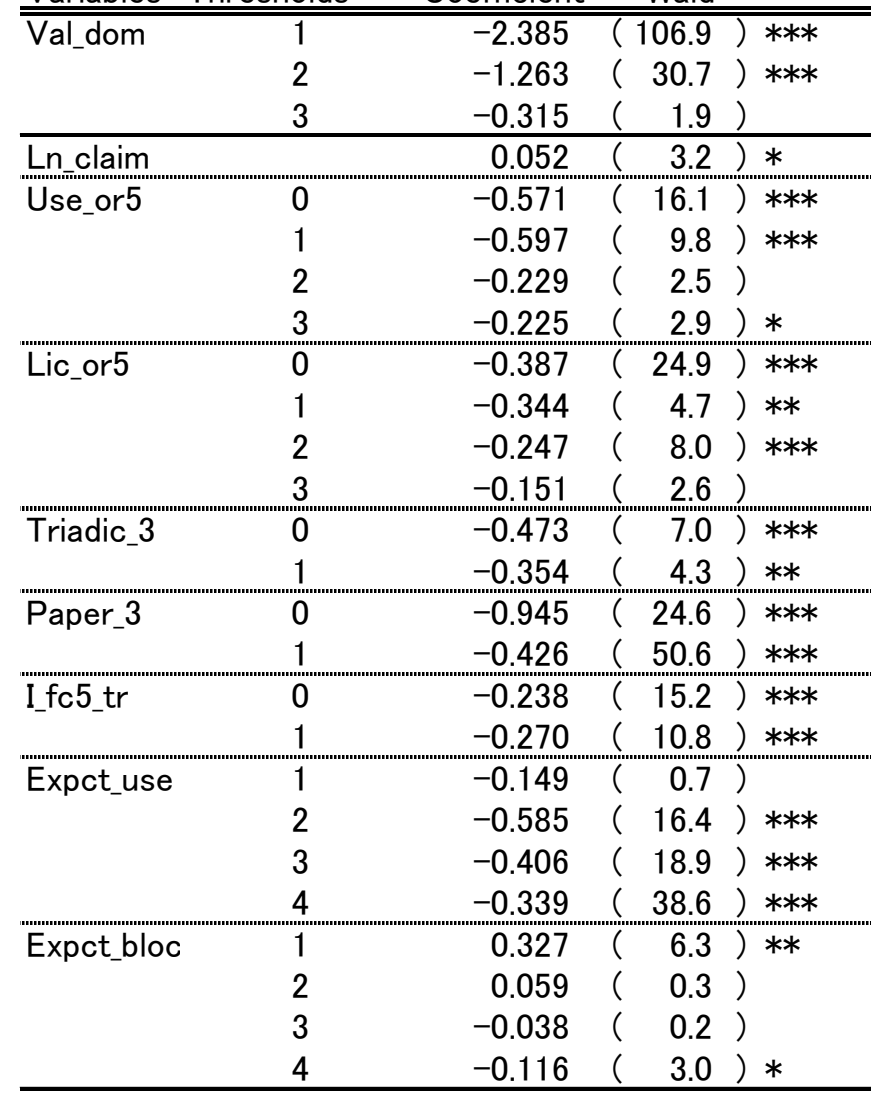

$*: 10 \%, \quad * *: 5 \%, \quad * * *: 1 \%$ significant 
Table.6 Comparative results of FIML estimate and Bayes estimates

\begin{tabular}{|c|c|c|c|c|}
\hline \multirow[b]{2}{*}{ Non-explanatory } & & \multirow[b]{2}{*}{ Explanatory } & \multicolumn{2}{|c|}{ Standardized Coefficient } \\
\hline & & & FIML & Bayes \\
\hline Variable & & Variable & Estimate & Estimate \\
\hline Val_dom & $\leftarrow$ & Tech Value & 0.375 & 0.426 \\
\hline Val_dom & $\leftarrow$ & Business Value & 0.260 & 0.275 \\
\hline Triadic_3 & $\leftarrow$ & Tech Value & 0.319 & 0.420 \\
\hline Use_or5 & $\leftarrow$ & Business Value & 0.612 & 0.627 \\
\hline Lic_or5 & $\leftarrow$ & Business Value & 0.290 & 0.329 \\
\hline Paper_3 & $\leftarrow$ & Tech Value & 0.593 & 0.716 \\
\hline Ln_claim & $\leftarrow$ & Tech Value & 0.199 & 0.205 \\
\hline I_fc5_tr & $\leftarrow$ & Tech Value & 0.256 & 0.323 \\
\hline Expct_use & $\leftarrow$ & Business Value & 0.339 & 0.388 \\
\hline Expct_bloc & $\leftarrow$ & Business Value & 0.214 & 0.253 \\
\hline Mot_sci & $\leftarrow$ & SciTech_Motive & 0.834 & 0.884 \\
\hline Mot_tech & $\leftarrow$ & SciTech_Motive & 0.518 & 0.574 \\
\hline Mot_car & $\leftarrow$ & Private_Motive & 0.711 & 0.739 \\
\hline Mot_mony & $\leftarrow$ & Private_Motive & 0.581 & 0.610 \\
\hline AcNW & $\leftarrow$ & Academic_Link & 0.575 & 0.841 \\
\hline Num_SL & $\leftarrow$ & Academic_Link & 0.386 & 0.529 \\
\hline InConc_sci & $\leftarrow$ & Academic_Inf & 0.505 & 0.554 \\
\hline InConc_ac & $\leftarrow$ & Academic_Inf & 0.924 & 0.951 \\
\hline InConc_gov & $\leftarrow$ & Academic_Inf & 0.836 & 0.861 \\
\hline Business Value & $\leftarrow$ & Academic_Link & -0.332 & -0.316 \\
\hline Tech Value & $\leftarrow$ & Academic_Link & 0.620 & 0.557 \\
\hline Business Value & $\leftarrow$ & SciTech_Motive & 0.244 & 0.278 \\
\hline Tech Value & $\leftarrow$ & SciTech_Motive & 0.253 & 0.257 \\
\hline
\end{tabular}


Table.7 Estimation Coefficient Results by Technological Field and Standardization

\begin{tabular}{|c|c|c|c|c|c|c|c|c|c|}
\hline $\begin{array}{l}\text { Non-explanatory } \\
\text { variable }\end{array}$ & & $\begin{array}{l}\text { Explanatory } \\
\text { variable }\end{array}$ & All fields & Chem & Drug & Comp & Elec & Mech & Others \\
\hline Val_dom & $\leftarrow$ & Tech Value & 0.38 & 0.29 & 0.37 & 0.42 & 0.35 & 0.47 & 0.41 \\
\hline Val_dom & $\leftarrow$ & Business Value & 0.26 & 0.33 & 0.43 & 0.07 & 0.29 & 0.19 & 0.19 \\
\hline Triadic_3 & $\leftarrow$ & Tech Value & 0.32 & 0.16 & -0.03 & 0.42 & 0.29 & 0.29 & 0.37 \\
\hline Paper_3 & $\leftarrow$ & Tech Value & 0.59 & 0.57 & 0.78 & 0.57 & 0.62 & 0.55 & 0.56 \\
\hline Ln_claim & $\leftarrow$ & Tech Value & 0.20 & 0.06 & 0.14 & 0.28 & 0.25 & 0.18 & 0.16 \\
\hline I_fc5_tr & $\leftarrow$ & Tech Value & 0.26 & 0.19 & 0.09 & 0.26 & 0.24 & 0.26 & 0.30 \\
\hline Use_or5 & $\leftarrow$ & Business Value & 0.61 & 0.72 & 0.38 & 0.03 & 0.58 & 0.60 & 0.65 \\
\hline Lic_or5 & $\leftarrow$ & Business Value & 0.29 & 0.30 & 0.12 & -0.06 & 0.18 & 0.32 & 0.33 \\
\hline Expct_use & $\leftarrow$ & Business Value & 0.34 & 0.34 & 0.51 & 0.50 & 0.32 & 0.43 & 0.30 \\
\hline Expct_bloc & $\leftarrow$ & Business Value & 0.21 & 0.20 & 0.36 & 0.83 & 0.12 & 0.26 & 0.21 \\
\hline Mot_sci & $\leftarrow$ & SciTech_Motive & 0.83 & 0.83 & 1.06 & 0.75 & 0.90 & 0.80 & 0.81 \\
\hline Mot_tech & $\leftarrow$ & SciTech_Motive & 0.52 & 0.53 & 0.39 & 0.54 & 0.52 & 0.56 & 0.52 \\
\hline Mot_car & $\leftarrow$ & Private_Motive & 0.71 & 0.71 & 0.52 & 0.75 & 0.79 & 0.73 & 0.68 \\
\hline Mot_mony & $\leftarrow$ & Private_Motive & 0.58 & 0.61 & 0.59 & 0.51 & 0.56 & 0.56 & 0.64 \\
\hline AcNW & $\leftarrow$ & Academic_Link & 0.58 & 0.75 & 0.62 & 0.50 & 0.55 & 0.54 & 0.52 \\
\hline Num_SL & $\leftarrow$ & Academic_Link & 0.39 & 0.26 & 0.40 & 0.40 & 0.30 & 0.17 & 0.37 \\
\hline InConc_sci & $\leftarrow$ & Academic_Inf & 0.51 & 0.39 & 0.46 & 0.51 & 0.49 & 0.50 & 0.59 \\
\hline InConc_ac & $\leftarrow$ & Academic_Inf & 0.92 & 1.00 & 0.85 & 0.87 & 0.94 & 0.92 & 0.90 \\
\hline InConc_gov & $\leftarrow$ & Academic_Inf & 0.84 & 0.77 & 0.84 & 0.88 & 0.86 & 0.85 & 0.84 \\
\hline Business Value & $\leftarrow$ & Academic_Link & -0.33 & -0.25 & -0.42 & -0.37 & -0.25 & -0.32 & -0.41 \\
\hline Tech Value & $\leftarrow$ & Academic_Link & 0.62 & 0.75 & 0.78 & 0.45 & 0.68 & 0.57 & 0.46 \\
\hline Business Value & $\leftarrow$ & SciTech_Motive & 0.24 & 0.12 & 0.26 & 0.18 & 0.22 & 0.31 & 0.28 \\
\hline Tech Value & $\leftarrow$ & SciTech_Motive & 0.25 & 0.24 & -0.01 & 0.42 & 0.28 & 0.32 & 0.24 \\
\hline
\end{tabular}




\section{Appended Table: Estimation Results for all Parameters}

\section{Most Likelihood Estimation}

\section{Coefficient:}

\begin{tabular}{|c|c|c|c|c|c|c|}
\hline & & & Estimated Value & Standard Error & Test Statistic & Probability \\
\hline Business Value & $<--$ & Academic_Link & -1.037 & 0.122 & -8.526 & $* * *$ \\
\hline Tech Value & $<--$ & Academic_Link & 0.669 & 0.051 & 13.184 & $* * *$ \\
\hline Business Value & $<--$ & SciTech_Motive & 0.216 & 0.026 & 8.143 & $* * *$ \\
\hline Tech Value & $<--$ & SciTech_Motive & 0.077 & 0.009 & 8.438 & $* * *$ \\
\hline Use_or5 & $<--$ & Business Value & 1 & & & \\
\hline Lic_or5 & $<---$ & Business Value & 0.523 & 0.042 & 12.401 & $* * *$ \\
\hline I_fc5_tr & $<--$ & Tech Value & 0.749 & 0.063 & 11.916 & $* * *$ \\
\hline Val_dom & $<---$ & Tech Value & 1.315 & 0.088 & 14.858 & $* * *$ \\
\hline Expct_bloc & $<---$ & Business Value & 0.274 & 0.03 & 9.026 & $* * *$ \\
\hline Val_dom & $<--$ & Business Value & 0.315 & 0.034 & 9.156 & $* * *$ \\
\hline Expct_use & $<--$ & Business Value & 0.401 & 0.031 & 12.744 & $* * *$ \\
\hline InConc_gov & $<--$ & Academic_Inf & 1 & & & \\
\hline InConc_ac & $<--$ & Academic_Inf & 1.154 & 0.029 & 39.64 & $* * *$ \\
\hline InConc_sci & $<--$ & Academic_Inf & 0.585 & 0.021 & 28.153 & $* * *$ \\
\hline AcNW & $<--$ & Academic_Link & 1 & & & \\
\hline Num_SL & $<---$ & Academic_Link & 0.838 & 0.052 & 15.976 & $* * *$ \\
\hline Mot_mony & $<--$ & Private_Motive & 0.795 & 0.052 & 15.37 & $* * *$ \\
\hline Mot_sci & $<---$ & SciTech_Motive & 1 & & & \\
\hline Mot_tech & $<--$ & SciTech_Motive & 0.464 & 0.024 & 19.358 & $* * *$ \\
\hline Ln_claim & $<--$ & Tech Value & 0.621 & 0.057 & 10.883 & $* * *$ \\
\hline Triadic_3 & $<--$ & Tech Value & 0.566 & 0.035 & 16.246 & $* * *$ \\
\hline Paper_3 & $<--$ & Tech Value & 1 & & & \\
\hline Mot_car & $<--$ & Private_Motive & 1 & & & \\
\hline
\end{tabular}

\section{Intercept :}

\begin{tabular}{|lrrrr|}
\hline & Estimated Value & Standard & Error & Test \\
\hline Val_dom & 2.096 & 0.015 & 138.282 & Probability \\
Use_or5 & 1.976 & 0.018 & 110.656 & $* * *$ \\
Lic_or5 & 1.194 & 0.02 & 59.912 & $* * *$ \\
Paper_3 & 1.13 & 0.006 & 177.654 & $* * *$ \\
Ln_claim & 1.683 & 0.012 & 144.561 & $* * *$ \\
Iffc5_tr & 0.517 & 0.013 & 40.772 & $* * *$ \\
Expct_use & 4.134 & 0.015 & 279.037 & $* * *$ \\
Expct_bloc & 3.715 & 0.016 & 230.221 & $* * *$ \\
Triadic_3 & 0.731 & 0.007 & 110.23 & $* * *$ \\
InConc_gov & 2.574 & 0.019 & 133.422 & $* * *$ \\
InConc_ac & 2.649 & 0.02 & 134.562 & $* * *$ \\
InConc_sci & 3.691 & 0.016 & 228.849 & $* * *$ \\
AcNW & 0.136 & 0.006 & 22.422 & $* * *$ \\
Num_SL & 0.193 & 0.008 & 25.658 & $* * *$ \\
Mot_car & 2.836 & 0.015 & 186.695 & $* * *$
\end{tabular}




\begin{tabular}{|lcccc|} 
Mot_mony & 2.736 & 0.015 & 185.189 & $* * *$ \\
Mot_sci & 3.571 & 0.015 & 240.574 & $* * *$ \\
Mot_tech & 4.245 & 0.011 & 384.912 & $* * *$ \\
\hline
\end{tabular}

Variance:

\begin{tabular}{|c|c|c|c|c|}
\hline & Estimated Value & Standard Error & Test Statistic & Probability \\
\hline Academic_Inf & 0.798 & 0.033 & 23.869 & $* * *$ \\
\hline Academic_Link & 0.063 & 0.005 & 13.313 & $* * *$ \\
\hline Private_Motive & 0.593 & 0.043 & 13.869 & $* * *$ \\
\hline SciTech_Motive & 0.786 & 0.043 & 18.302 & $* * *$ \\
\hline eS & 0.033 & 0.004 & 8.285 & $* * *$ \\
\hline $\mathrm{eP}$ & 0.54 & 0.046 & 11.746 & $* * *$ \\
\hline e2 & 1.826 & 0.04 & 45.956 & $* * *$ \\
\hline e0 & 0.632 & 0.02 & 32.003 & $* * *$ \\
\hline e7 & 0.584 & 0.014 & 41.986 & $* * *$ \\
\hline e5 & 0.135 & 0.004 & 30.796 & $* * *$ \\
\hline e3 & 0.762 & 0.019 & 39.108 & $* * *$ \\
\hline e6 & 0.683 & 0.014 & 49.94 & $* * *$ \\
\hline e8 & 0.208 & 0.004 & 47.63 & $* * *$ \\
\hline e1 & 1.025 & 0.045 & 22.638 & $* * *$ \\
\hline e4 & 0.955 & 0.023 & 41.95 & $* * *$ \\
\hline e23 & 0.345 & 0.019 & 17.966 & $* * *$ \\
\hline e22 & 0.182 & 0.023 & 8.017 & $* * *$ \\
\hline e21 & 0.798 & 0.02 & 39.387 & $* * *$ \\
\hline e24 & 0.127 & 0.005 & 27.888 & $* * *$ \\
\hline e25 & 0.252 & 0.006 & 43.549 & $* * *$ \\
\hline e13 & 0.581 & 0.039 & 14.759 & $* * *$ \\
\hline e11 & 0.736 & 0.028 & 26.373 & $* * *$ \\
\hline e15 & 0.46 & 0.012 & 37.766 & $* * *$ \\
\hline e14 & 0.345 & 0.038 & 9.078 & $* * *$ \\
\hline
\end{tabular}

Covariance, correlation coefficient;

\begin{tabular}{|c|c|c|c|c|c|c|c|}
\hline & & & $\begin{array}{r}\text { Estimated } \\
\text { Value } \\
\end{array}$ & $\begin{array}{r}\text { Standard } \\
\text { Error }\end{array}$ & $\begin{array}{r}\text { Test } \\
\text { Statistic } \\
\end{array}$ & Probability & $\begin{array}{l}\text { Correlation } \\
\text { Coefficient }\end{array}$ \\
\hline Academic_Inf & $\langle->$ & Academic_Link & 0.101 & 0.007 & 14.984 & $* * *$ & 0.448 \\
\hline Academic_Inf & $\langle->$ & Private_Motive & 0.169 & 0.017 & 10.2 & $* * *$ & 0.246 \\
\hline SciTech_Motive & $\langle->$ & Academic_Inf & 0.281 & 0.018 & 15.483 & $* * *$ & 0.355 \\
\hline SciTech_Motive & $\langle->$ & Academic_Link & 0.07 & 0.006 & 12.32 & $* * *$ & 0.316 \\
\hline SciTech_Motive & $\langle->$ & Private_Motive & 0.273 & 0.016 & 17.087 & $* * *$ & 0.4 \\
\hline eS & $\langle--\rangle$ & $\mathrm{eP}$ & 0.123 & 0.007 & 16.575 & $* * *$ & 0.917 \\
\hline
\end{tabular}

